\title{
Elfriede Jelinek
}

\section{Notes on Secondary Drama}

As a boost to the business of theatre, I am now ready to offer an increased supply of secondary dramas meant to run, barking, along the classics (or as wallpaper to be rolled out behind them and pasted to a wall. I already tested it once with Lessing's Nathan the Wise, but now I gratefully accept orders also for other dramas for which I will provide secondary dramas. Shakespeare is the only one I would not do that to on principle. But I will gratefully accept all other orders; currently Goethe's Urfaust is in the works, two down, more to go, maybe, but without me, for art doesn't go along with me, it rather goes against me, an ongoing guilt, but guilelessly so). Thus, as an artist I might have found a new strategy, this time on the safe side, because people are always watching the classics and people will forever see them; I can also viking-ize them, bleach them blond or even give them a perm. None of it has to last forever. None of it should last forever. The last thing the classics need is being sustained or entertained by me. However, I will fail once again, because, as usual, I won't understand the specifics of a given classic (or I'll get it all wrong); so I'll either write the right secondary drama for the wrong play, or, more likely, I won't understand the original drama and add something totally wrong. Although, whatever I write is always wrong to begin with. However, if the specifics are wrong (and that is also a specialty of mine, at math tests I always copied the specifics on the blackboard incorrectly), none of my speechifying will do me any good; I am barking up the wrong tree and I stop being an artist, at least for the duration of my failing project. I am a secondary artist, but perhaps I will still be able to submit a new application as a primary artist. In any event many thanks for letting me introduce a small excerpt from my extensive catalogue.

A word with regard to staging: the options are unlimited. The main drama could integrate scenes from the side drama, the text could be run as a ticker in the back, it could also just be just heard from off stage like a radio play, or spoken, even performed on stage alongside the main play. The main play can briefly recede to make room for the secondary play and vice versa. Spectators can download the text to read along on their laptops or smart phones (there could even be an app for secondary dramas). The secondary play can replace parts of the main play, but there is one thing it must not do: the secondary

Copyright by Elfriede Jelinek. Published with the kind permission of Rowohlt Verlag GmbH, Reinbek bei Hamburg. 
play can never be presented as the main drama, as a solo, so to speak. One modifies the other, the secondary drama derives from the main drama and accompanies it, in different ways, but it always is: accompaniment. The secondary drama is a companion piece. That takes a lot of stress off me, phew, and so I am glad I invented the secondary drama for my own relief and to release upon the great who have to struggle with it, no, they don't really have to, but they can if they want to.

Translated from the German by Gitta Honegger. 